\title{
Characterization and Cytotoxicity Evaluation of Biologically Synthesized Silver Nanoparticles from Albuca setosa aqueous bulb extract
}

\section{Samuel W Odeyemi, Anthony J Afolayan}

University of Fort Hare, South Africa

Biologically synthesized nanoparticles are rapidly evolved due to cost effectiveness and Eco friendliness. This also contributes to its preference over nanoparticles from other sources.

In the present study silver nanoparticles are synthesized from Albuca setosa aqueous bulb extracts (ASB) and evaluate the biological activities. The silver nanoparticles were synthesized from Albuca setosa aqueous bulb extracts using silver nitrate and characterized using UV-visible spectroscopy Fourier transform infrared spectroscopy scanning electron microscope Energy Dispersive X ray Spectroscopy X ray diffraction and transmission electron microscopy.

The antioxidant activity was determined by evaluating the effect on 22 diphenyl 2 picrylhydrazyl (DPPH) scavenging activity 22 azino bis (3 ethylbenzthiazoline 6 sulfonic acid diammonium salt (ABTS).

The antibacterial potential was investigated on selected Gram positive and Gram negative bacteria. While the cytotoxicity was evaluated on MDA MB231 breast cancer cells.

Albuca setosa silver nanoparticles (AS AgNPs) showed stable irregular shaped well dispersed crystalline silver nanoparticles with average size of $7 \mathrm{~nm}$. The XRD patterns revealed four diffraction peaks at $54.78,57.63,76.91,85.75$ and 92.37 degrees that was indexed to $\left(\begin{array}{lll}1 & 1 & 0\end{array}\right)\left(\begin{array}{lll}1 & 1 & 0\end{array}\right)\left(\begin{array}{lll}1 & 0 & 0\end{array}\right)\left(\begin{array}{lll}1 & 0 & 0\end{array}\right)$ and $\left(\begin{array}{lll}1 & 0 & 0\end{array}\right)$ planes of face-centered cubic (fcc) structure respectively.

The synthesized nanoparticles possess good antioxidant activity with IC50 of 78.89 and $397.16 \mathrm{ug} / \mathrm{ml}$ for DPPH and ABTS respectively and inhibits the growth of Staphylococcus faecalis and Bacillus cereus with MIC of 25 and $15 \mathrm{ug} / \mathrm{ml}$ respectively.

The synthesized AS-AgNPs revealed higher cytotoxic efficacy against MDA MB231 breast cancer cells with IC50 of 64.52 $\mathrm{ug} / \mathrm{ml}$.

In summary AS-AgNPs showed acceptable size and shape of nanoparticles and could therefore be a potential source of antimicrobial and anti-cancer agents. 